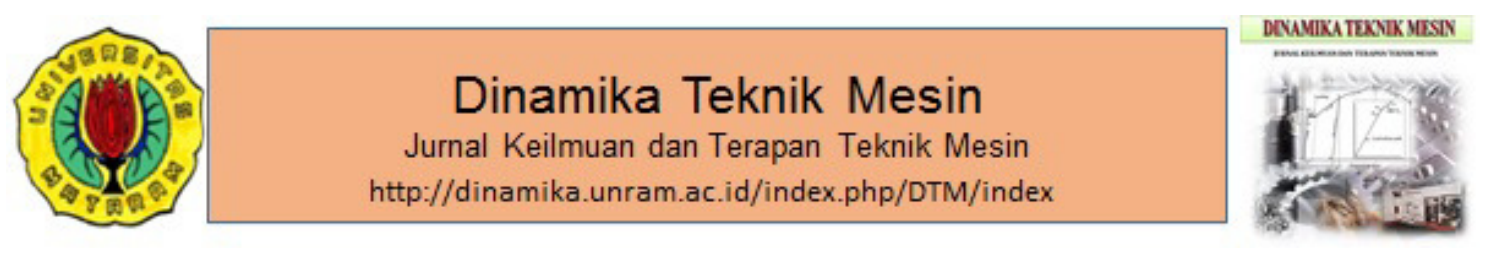

\title{
Pengaruh variasi pembagian jumlah anoda dengan pola horisontal terhadap laju korosi baja SS400 pada media air laut
}

\author{
A. Faisol *, Sumarji, G. Djatisukamto \\ Teknik Mesin Fakultas Teknik Universitas Jember, Jln. Kalimantan 37, Jember \\ Kode Pos : 68121, Telp. (0331) 410243 Fax (0331) 484977. \\ *Email: akhmadfaisol2013@gmail.com
}

\section{ARTICLE INFO}

Article History:

Received 30 September 2017

Accepted 22 October 2017

Available online 1 January 2018

Keywords:

Sacrificial anode

Weight loss

Resistivity

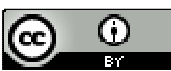

\begin{abstract}
Sacrificial anode protection is one type of corrosion protection used to inhibit corrosion rate. The sacrificial anode protection works by utilizing the potential difference between anode and cathode. This research aims to determine the effect of variation in the distribution of quantities and distribution of sacrificial anode aluminum to SS400 steel corrosion rate. The method of calculating the corrosion rate used is the weight loss test. The results of this test indicate that the more uniform distribution of the anode on the surface of the cathode the better the resulting protection will be. The best protection is produced by 4 pieces of sacrificial anode size of $0,5 \times 4 \mathrm{~cm}$ with an average rate of corrosion rate of $0,1067 \mathrm{~mm} /$ year. Protection with 2 pieces of sacrificial anode size $1 \times 4$ $\mathrm{cm}$ resulted in corrosion rate with average value $0,1462 \mathrm{~mm} /$ year, while on protection of 1 victim anode with size $2 \times 4 \mathrm{~cm}$ can produce protection with average value of corrosion rate $0,1677 \mathrm{~mm} /$ year. Equivalent distribution of numbers and distributed anodes can narrow the distance between the anodes so that the value of the material's resitivity is smaller and the electrons can be distributed evenly over the entire cathode surface. The corrosion that occurs in SS400 steel is a kind of uniform corrosion. It is seen from the size of the cavity that occurs on each side of the specimen after the immersion process.
\end{abstract}

\section{PENDAHULUAN}

Degradasi material disebabkan oleh pengaruh media terhadap logam. Baja banyak dimanfaatkan sebagai material kontruksi kapal dan jembatan dimana rentan terserang korosi, $13 \%$ besi atau baja baru hasil pengolahan digunakan setiap tahunnya untuk mengganti besi yang terkorosi (Widharto, 1997). Korosi adalah reaksi kimia antara logam dengan lingkungan. Logam yang terserang korosi akan mengalami penurunan kualitas sifat fisik dan mekaniknya. Korosi akan menurunkan umur logam. Proses korosi tidak mungkin dihentikan, akan tetapi diperlukan metode bagaimana menurunkan laju korosi serendah-rendahnya (Rey dan Pryitno, 2015). 
Metode proteksi katodik yang sering digunakan adalah sistem anoda korban sedangkan sistem arus tanding jarang digunakan dan jenis anoda korban yang sering digunakan adalah paduan seng dan aluminium (BKI, 2006). Baja SS400 sering digunakan sebagai bahan lambung kapal, rentan mengalami serangan korosi, sehingga perlu dilakukan perawatan sekaligus proteksi korosi agar tidak terjadi kerusakan yang dapat mengancam keselamatan kerja.

Arus yang dihasilkan sistem proteksi anoda korban sangat terbatas karena hanya berasal dari beda potensial antara anoda dan katoda, sistem ini akan memakan biaya yang besar bila digunakan untuk memproteksi struktur yang luas karena akan membutuhkan jumlah anoda yang banyak. Saat proses pemasangan anoda lapisan coating dari katoda harus dihilangkan, hal ini bertujuan agar aliran arus dari anoda lebih efektif, tidak terhambat oleh coating (Wiludin dan Soepomo, 2013). Ketersediaan arus yang lebih kecil dari arus kebutuhan proteksi dapat menyebabkan kerusakan, proses pendistribusian anoda korban harus dilakukan dengan merata agar arus proteksi dapat menjangkau semua bagian logam, selain itu resistivitas dari material dapat menyebabkan terhambatnya arus proteksi.

Nilai potensi paling negatif diperoleh bagian yang berada paling dekat dengan anoda korban. Semakin bertambahnya jarak dengan anoda maka proteksi yang diberikan akan semakin kecil (Morgan, 1987). Penyebaran arus yang tidak merata akan mengakibatkan bagian yang tidak terkena arus anoda akan mengalami kerusakan terlebih dahulu dibandingkan yang lain (Putra dkk., 2014). Jenis bentuk anoda dipilih dengan memperhatikan bentuk katoda, dimana untuk aplikasi plat baja yang memiliki panjang 4 kali lebih besar dari tebal maka jenis anoda yang digunakan adalah long flush mounted dengan nilai faktor guna 0,85 yang nantinya akan digunakan untuk dasar perhitungan kebutuhan berat anoda (Fontana dan Mars, 1986).

Berdasarkan beberapa landasan tersebut pembagian jumlah anoda dan pendistribusian letak anoda sangat berpengaruh terhadap laju korosi plat baja dengan ukuran panjang lebih besar dari 4 kali tebal maka desain anoda yang digunakan adalah long flush mounted, oleh sebab itu penelitian ini akan dilakukan guna mengetahui pengaruh variasi pembagian jumlah anoda dengan pola horisontal pada baja SS400.

\section{METODE PENELITIAN \\ Perendaman spesimen}

Pengujian spesimen baja SS400 menggunakan jenis pengujian immersion dengan mengacu pada standart ASTM G71-81 Standard Guide for Conducting and Evaluating Galvanic Corrosion Tests in Electrolytes.

Laju korosi dapat dihitung menggunakan rumus dengan formula sebagai berikut :

$C R=\frac{K W}{A D T}$

Dimana $C R$ adalah laju korosi (mm/th), W menyatakan massa yang terkorosi (gram), $A$ adalah luas tercelup $\left(\mathrm{cm}^{2}\right), K$ adalah konstanta $8,76 \times 10^{4}, T$ sebagai waktu (jam) dan $D$ adalah densitas $\left(\mathrm{gram} / \mathrm{cm}^{3}\right)$.

Variabel bebas merupakan variabel yang ditentukan oleh peneliti secara bebas. Variabel ini akan menjadikan patokan untuk mengetahui hasil dari penelitian. Variabel bebas yang digunakan adalah pembagian jumlah dan posisi peletakan anoda korban.

Variabel terikat merupakan variabel dimana besarnya akan mengikuti besarnya variabel bebas sehingga tidak dapat ditentukan oleh peneliti. Variabel terikat yang digunakan adalah luas total anoda korban pada setiap variasi.

\section{Prosedur Penelitian}

1. Langkah awal yang perlu dilakukan adalah persiapan alat dan bahan yang akan digunakan untuk kesiaapan pengujian.

2. Memotong plat baja SS400 dan aluminium sesuai ukuran pada setiap variasi.

3. Menimbang berat awal spesimen baja SS400 sebelum proses perendaman.

4. Merendam spesimen pada media air laut dengan interval waktu 1, 2, 3, dan 4 minggu.

5. Menimbang berat akhir spesimen setalah proses perendaman.

6. Pengolahan data.

\section{Desain spesimen $\mathbf{u j i}$}

a. Spesimen baja SS400 dengan proteksi 1 buah anoda ukuran $2 \times 4 \mathrm{~cm}$ dapat dilihat pada gambar nomer 1.

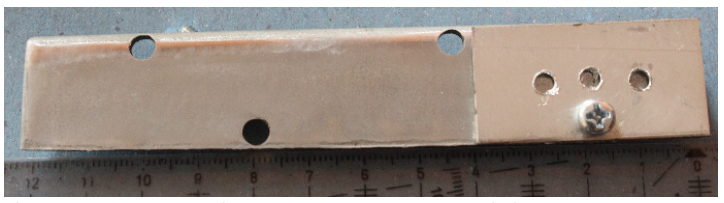

Gambar 1. Spesimen baja SS400 dengan proteksi 1 buah anoda ukuran $2 \times 4 \mathrm{~cm}$

b. Spesimen baja SS400 dengan proteksi 2 buah anoda ukuran $1 \times 4 \mathrm{~cm}$ dapat dilihat pada gambar nomer 2. 


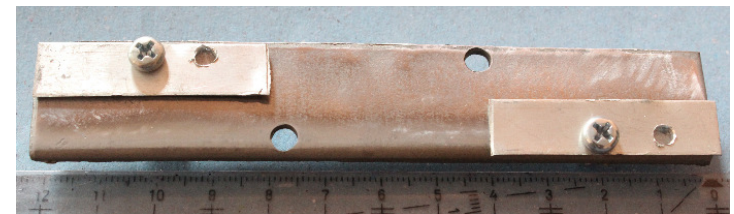

Gambar 2. Spesimen baja SS400 dengan proteksi 2 buah anoda ukuran $1 \times 4 \mathrm{~cm}$

c. Spesimen baja SS400 dengan proteksi 4 buah anoda ukuran $0,5 \times 4 \mathrm{~cm}$ dapat dilihat pada gambar nomer 3 .

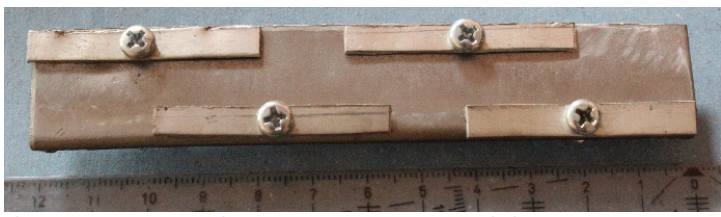

Gambar 3. Spesimen baja SS400 dengan proteksi 4 buah anoda ukuran $0,5 \times 4 \mathrm{~cm}$

\section{Perhitungan kebutuhan berat anoda korban}

Kebutuhan berat anoda korban untuk memproteksi baja SS400 dengan luas 52,815 $\mathrm{cm}^{2}$ dapat dihitung dengan persamaan:

$$
M=\frac{8760 I C T}{\mu \varepsilon}=0,208 \mathrm{gr}
$$

Dimana $M$ adalah berat kebutuhan anoda kurban, IC menyatakan kebutuhan arus proteksi yaitu sebesar 0,01346 mA, $A c$ adalah luas pelat baja yang diproteksi dengan paduan aluminium $\left(\mathrm{m}^{2}\right)$ sebesar $52,82 \mathrm{~cm}^{2}$.

$$
f c=k 1+k 2+\frac{t f}{2}
$$

fc diperoleh 0,0425 Ampere untuk $k 1=0,02, k 2=$ 0,015 , tf adalah umur proteksi 3 tahun (Standar $\mathrm{BKI})$, ic adalah arus densitas rata-rata $\left(\mathrm{A} / \mathrm{m}^{2}\right)$ sebesar 0,060 Ampere $/ \mathrm{m}^{2}, \mu=0,85, \varepsilon=2000$ untuk paduan aluminium, $T=3$ tahun (Standar $\mathrm{BKI})$.

\section{Komposisi baja SS400}

Komposisi unsur kimia spesimen baja SS400 dapat dilihat pada tabel nomer 1 .

Tabel 1 Komposisi unsur kimia baja SS400

\begin{tabular}{cc}
\hline Unsur & Prosentase $(\%)$ \\
\hline $\mathrm{C}$ & 0,29312 \\
$\mathrm{Si}$ & 0,34756 \\
$\mathrm{Mn}$ & 0,41974 \\
$\mathrm{P}$ & 0,02109 \\
$\mathrm{~S}$ & 0,03931 \\
\hline
\end{tabular}
dengan pola horisontal terhadap laju korosi baja SS400

\begin{tabular}{cc}
\hline $\mathrm{Cu}$ & 0,49226 \\
$\mathrm{Ni}$ & 2,0134 \\
$\mathrm{Cr}$ & 0,47754 \\
$\mathrm{Mo}$ & 0,92891 \\
$\mathrm{Al}$ & 0,01007 \\
$\mathrm{Fe}$ & 94,957 \\
\hline
\end{tabular}

\section{HASIL DAN PEMBAHASAN}

Analisis laju korosi baja SS400 tanpa anoda korban

Laju korosi yang terjadi pada spesimen baja SS400 tanpa proteksi anoda korban ditunjukkan pada gambar nomer 4 .

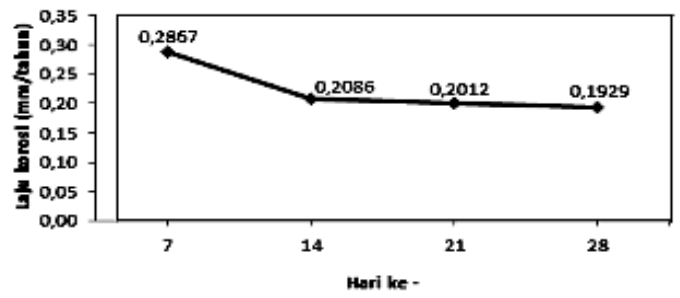

Gambar 4. Laju korosi spesimen baja SS400 tanpa anoda korban

Korosi baja SS400 tanpa proteksi anoda korban pada setiap interval waktu pengambilan data, pada spesimen uji minggu pertama kehilangan berat tertinggi $0,2348 \mathrm{~g}$ dengan nilai rata-rata laju korosi mencapai $0,2867 \mathrm{~mm} / \mathrm{tahun}$, pada pengambilan data minggu kedua kehilangan berat tertinggi mencapai $0,3451 \mathrm{~g}$ dengan rata-rata laju korosi $0,2086 \mathrm{~mm} /$ tahun. Pengambilan data pada minggu ketiga menunjukkan kehilangan berat mengalami kenaikan yang sangat signifikan dengan nilai tertinggi $0,5235 \mathrm{~g}$ dan rata-rata laju korosi 0,2012 $\mathrm{mm} / \mathrm{tahun}$, dan pada minggu ke 4 didapat nilai tertinggi dengan angka 0,6590 $\mathrm{g}$ dengan nilai laju korosi rata-rata berada pada angka 0,1929 $\mathrm{mm} /$ tahun. Penurunan rata-rata laju korosi pada setiap minggunya di karenakan semakin lama baja terkorosi maka lapisan karat akan semakin tebal, akibat lapisan karat yang tebal maka reaksi elektrokimia tidak berjalan dengan baik, karena dengan adanya lapisan karat maka lapisan ini berfungsi sebagai lapisan passivasi sehingga kandungan $\mathrm{Cl}^{-}$pada air laut tidak dapat menyerang logam (Muhsinin dan Kurniawan, 2012).

\section{Analisis laju korosi baja SS400 dengan proteksi 1 buah anoda korban}

Spesimen baja SS400 direndam pada media air laut selama 28 hari dengan proteksi 1 buah aluminium sebagai anoda korban berukuran $2 \times 4 \mathrm{~cm}$ guna mengetahui pengaruh 
penambahan aluminium terhadap laju korosi baja SS400. Setelah proses pengambilan data diketahui penurunan laju korosi pada baja SS400 dengan aplikasi anoda korban sangat signifikan, penurunan laju korosi dengan proteksi 1 buah anoda korban dapat dilihat pada gambar nomer 5.

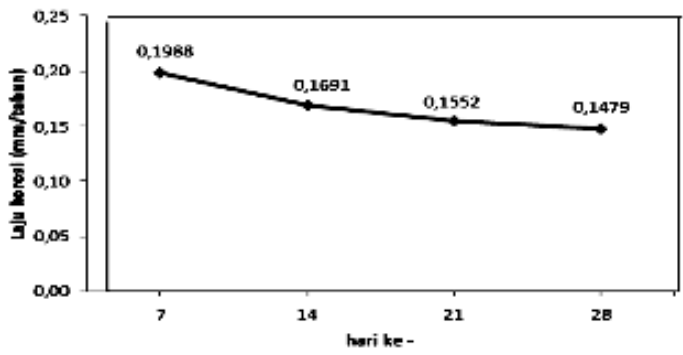

Gambar 5. Laju korosi spesimen baja SS400 dengan proteksi 1 buah aluminium ukuran $2 \times 4$ (cm)

Hasil perhitungan laju korosi pada baja SS400 yang di proteksi dengan 1 buah aluminium mengalami penurunan laju korosi yang sangat signifikan dibandingkan laju korosi baja tanpa perlindungan anoda, pada minggu pertama kehilangan berat tertinggi berada pada angka $0,1844 \mathrm{~g}$ dengan rata-rata laju korosi $0,1988 \mathrm{~mm} /$ tahun. Pengambilan data pada minggu kedua menunjukkan nilai kehilangan berat tertinggi 0,2832 g dengan nilai rata-rata laju korosi $0,1691 \mathrm{~mm} /$ tahun, pada pengambilan data minggu ketiga diperoleh kehilangan berat tertinggi $0,4065 \mathrm{~g}$ dengan rata-rata laju korosi 0,1552 $\mathrm{mm} /$ tahun, sedangkan pada pengambilan data minggu ke 4 diperoleh data tertinggi 0,4779 $\mathrm{g}$ dengan rata-rata laju korosi $0,1479 \mathrm{~mm} /$ tahun.

\section{Analisis laju korosi baja SS400 dengan proteksi 2 buah anoda korban}

Spesimen baja SS400 diproteksi dengan anoda korban dengan luas yang sama namun dengan distribusi yang berbeda, hal ini dilakukan untuk mengetahui pengaruh pembagian jumlah anoda terhadap laju korosi baja SS400, penurunan laju korosi dengan proteksi 2 buah anoda korban dapat dilihat pada gambar nomer 6.

Laju korosi yang dihasilkan baja SS400 dengan proteksi 2 buah anoda dengan ukuran 1 $\mathrm{x} 4 \mathrm{~cm}$ mengalami penurunan dibandingkan proteksi 1 buah anoda dengan ukuran $2 \times 4 \mathrm{~cm}$. Pada minggu pertama kehilangan berat tertinggi berada pada angka 0,1466 g dengan rata-rata laju korosi 0,1792 mm/tahun, pengambilan data minggu kedua nilai kehilangan berat tertinggi berada pada $0.2729 \mathrm{~g}$ dengan rata-rata laju korosi 0,1435 $\mathrm{mm} /$ tahun, pada minggu ke 3 kehilangan berat tertinggi $0,3302 \mathrm{~g}$ dengan ratarata laju korosi $0,1372 \mathrm{~mm} /$ tahun, sedangkan minggu ke 4 data kehilangan berat tertinggi berada pada angka $0,4026 \mathrm{~g}$ dengan rata-rata laju korosi $0,1250 \mathrm{~mm} /$ tahun.

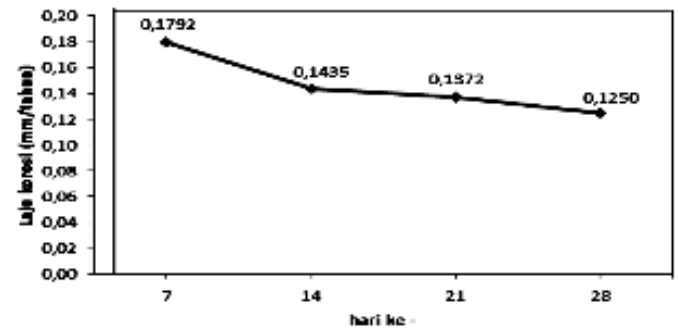

Gambar 6. Laju korosi spesimen baja SS400 dengan 2 buah aluminium ukuran 1 x 4 (cm)

\section{Analisis laju korosi baja SS400 dengan proteksi 4 buah anoda korban}

Spesimen baja SS400 diproteksi dengan 4 buah anoda korban dengan total luas yang sama, hal ini dilakukan untuk mengetahui pengaruh pembagian jumlah anoda terhadap laju korosi baja SS400, penurunan laju korosi dengan proteksi 4 buah anoda korban dapat dilihat pada gambar 7.

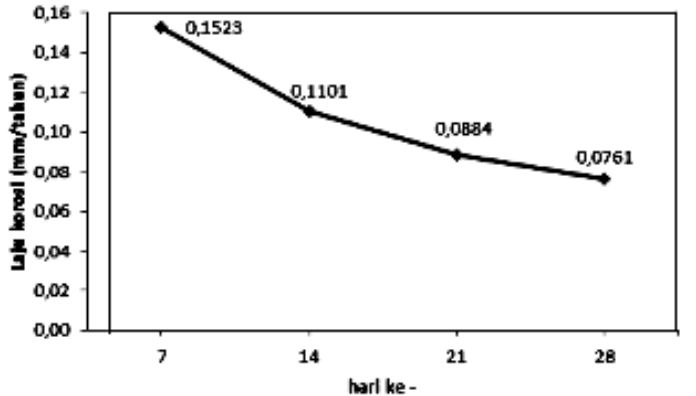

Gambar 7. Laju korosi spesimen baja SS400 dengan 4 buah aluminium 0,5 x $4(\mathrm{~cm})$

Laju korosi pada baja SS400 dengan proteksi 4 buah anoda berukuran 0,5 × $4 \mathrm{~cm}$ memiliki nilai yang paling kecil dibandingkan proteksi dengan 1 buah anoda dengan ukuran 2 x $4 \mathrm{~cm}$ dan 2 buah anoda ukuran $1 \times 4 \mathrm{~cm}$. Pada minggu pertama kehilangan berat tertinggi berada pada angka 0,1287 g dengan rata-rata laju korosi $0,1523 \mathrm{~mm} /$ tahun, pengambilan data minggu kedua nilai kehilangan berat tertinggi berada pada 0,1832 $\mathrm{g}$ dengan rata-rata laju korosi $0,1101 \mathrm{~mm} /$ tahun, pada minggu ke 3 kehilangan berat tertinggi $0,2124 \mathrm{~g}$ dengan ratarata laju korosi $0,0884 \mathrm{~mm} /$ tahun, sedangkan minggu ke 4 data kehilangan berat tertinggi berada pada angka 0,2501 g dengan rata-rata laju korosi 0,0761 $\mathrm{mm} /$ tahun. Penurunan laju 
korosi pada pengambilan data pada setiap minggunya terjadi karena pengaruh lapisan film pasif yang terbentuk setelah proses perendaman. Lapisan ini terbentuk karena oksidasi dengan udara yang menghambat laju korosi dan berbalik menjadi pelindung permukaan logam dari serangan korosi (Johanes, 2012).

\section{Analisis perbedaan laju korosi pada setiap} variasi anoda korban

Berdasarkan data rata-rata laju korosi yang terjadi pada setiap variasi dapat di munculkan grafik seperti yang ditunjukkan gambar nomer 8 dengan prosentase penurunan laju korosi ditunjukkan pada gambar nomer 9.

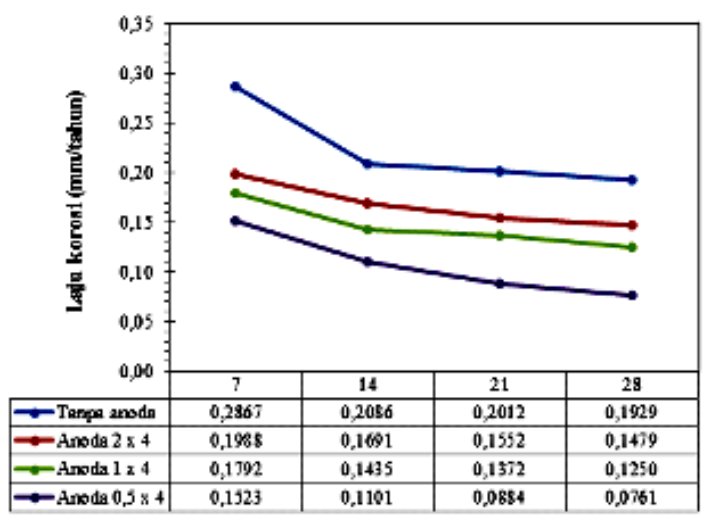

Gambar 8. Laju korosi spesimen baja SS400 pada setiap interval waktu pengangkatan

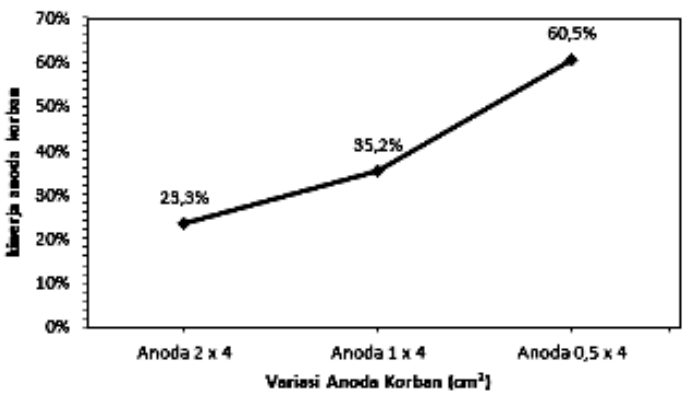

Gambar 9. Prosentase penurunan laju korosi spesimen baja SS400 per variasi terhadap spesimen tanpa anoda korban dalam interval waktu 28 hari

Berdasarkan gambar nomer 8 dan 9 dapat dilihat perbedaan laju korosi pada setiap variasi. Prosentase penurunan laju korosi terbesar diperoleh dengan menggunakan proteksi 4 buah anoda korban berukuran $0,5 \times 4 \mathrm{~cm}$, yaitu sebesar $60,5 \%$ sedangkan prosentase penurunan laju korosi terendah terdapat pada proteksi menggunakan 1 buah anoda korban dengan ukuran $2 \times 4 \mathrm{~cm}$ dengan prosentase sebesar $23,3 \%$, dan 2 buah anoda korban $1 \times 4$ $\mathrm{cm}$ memiliki prosentase penurunan laju korosi diantara kedua variasi anoda korban yang lainnya yaitu sebesar $35,2 \%$ terhadap baja tanpa anoda korban. Hal ini menunjukkan bahwa penggunaan anoda korban dapat memperlambat laju korosi terhadap baja SS400 pada media air laut, pendistribusian anoda yang merata pada permukaan logam terbukti meningkatkan perlindungan kepada katoda, hal ini disebabkan proses perpindahan elektron dari anoda menuju katoda terdistribusi secara merata sehingga permukaan yang terproteksi semakin luas.

Berbeda dengan proteksi menggunakan 1 buah anoda yang memusat pada satu titik, pemusatan anoda korban mengakibatkan perpindahan elektron yang pendek karena adanya hambatan jarak sehingga sisi katoda yang jauh dari anoda mengalami korosi yang lebih parah karena tidak terpasivasi oleh elektron. Semakin banyak sisisisi dari anoda yang melindungi katoda maka akan semakin baik perlindungan yang diberikan anoda ke katoda (Sulistioso, 2012).

\section{Observasi Struktur Makro \\ Analisis struktur makro baja SS400 setelah proses perendaman \\ Setelah spesimen melalui proses} perendaman terlihat produk korosi terbentuk pada permukaan logam, gambar 10-13 dibawah merupakan foto makro dari spesimen setelah proses perendaman hari ke 28 .

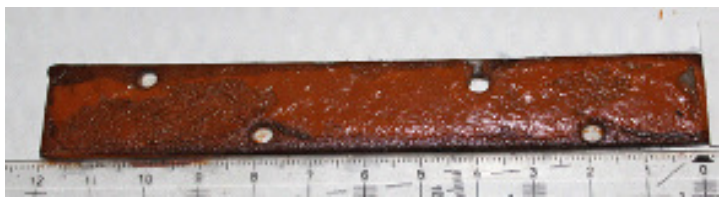

Gambar 10. Pengangkatan spesimen tanpa proteksi anoda koraban hari ke 28

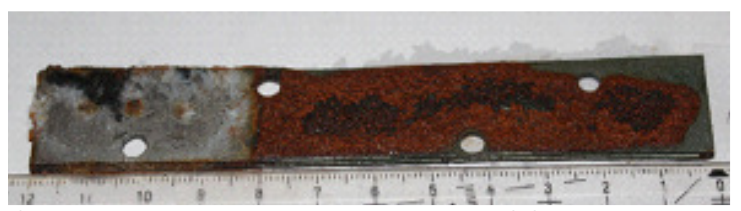

Gambar 11. Pengangkatan baja SS400 dengan proteksi 1 buah anoda korban ukuran $2 \times 4 \mathrm{~cm}$ hari ke 28

Berdasarkan foto makro diatas korosi yang terjadi pada baja yang diproteksi 4 buah anoda korban ukuran $0,5 \times 4 \mathrm{~cm}$ lebih sedikit dibandingkan variasi yang lain. Hal ini disebabkan letak aluminium yang merata sehingga proses passivasi dan perpindahan 
elektron dari anoda menuju katoda terjadi pada semua sisi katoda.

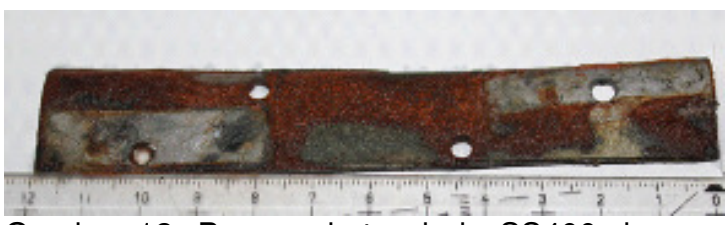

Gambar 12. Pengangkatan baja SS400 dengan proteksi 2 buah anoda korban ukuran 1 x $4 \mathrm{~cm}$ hari ke 28

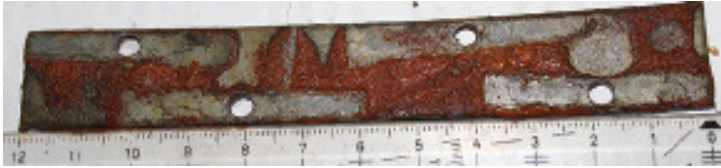

Gambar 13. Pengangkatan baja SS400 dengan proteksi 4 buah anoda korban ukuran $0,5 \times 4 \mathrm{~cm}$ hari ke 28

\section{Observasi Struktur Mikro}

Observasi mikro merupakan pengamatan yang dilakukan untuk mengetahui perbedaan struktur mikro antara baja S\$400 sebelum dan setelah proses perendaman pada air laut serta pengaruh aluminium sebagai anoda korban. Gambar 14 merupakan foto struktur mikro baja SS400 sebelum proses perendaman.

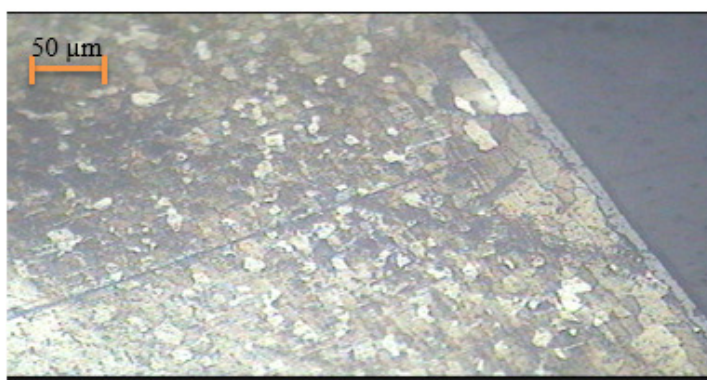

Gambar 14. Foto mikro baja SS400 sebelum proses perendaman

Gambar 14 menunjukkan bahwa sebelum proses perendaman kondisi baja SS400 masih dalam keadaan baik, terlihat pada batas antara resin dan logam belum ada rongga yang muncul akibat serangan korosi.

Setelah spesimen melalui proses perendaman perlu dilakukan observasi mikro untuk mengetahui jenis korosi yang terjadi, gambar 15-18 dibawah merupakan foto mikro dari spesimen setelah proses perendaman hari ke 28.

\section{dengan pola horisontal terhadap laju korosi baja SS400}

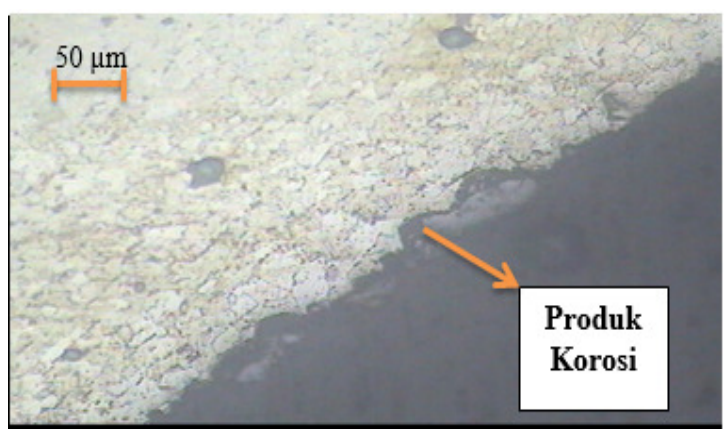

Gambar 15. Foto mikro baja SS400 tanpa proteksi anoda korban setelah perendaman 28 hari

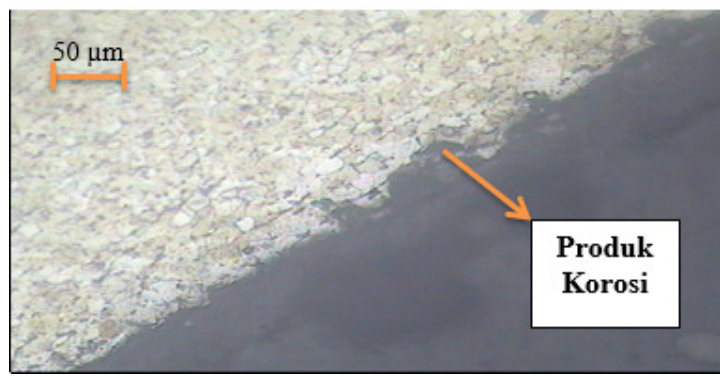

Gambar 16. Foto mikro baja SS400 dengan proteksi 1 buah aluminium ukuran $2 \times 4 \mathrm{~cm}$ setelah perendaman 28 hari

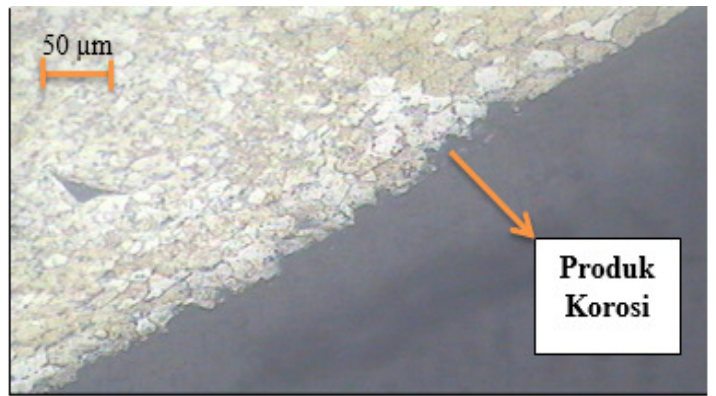

Gambar 17. Foto mikro baja SS400 dengan proteksi 2 buah aluminium ukuran $1 \times 4 \mathrm{~cm}$ setelah perendaman 28 hari

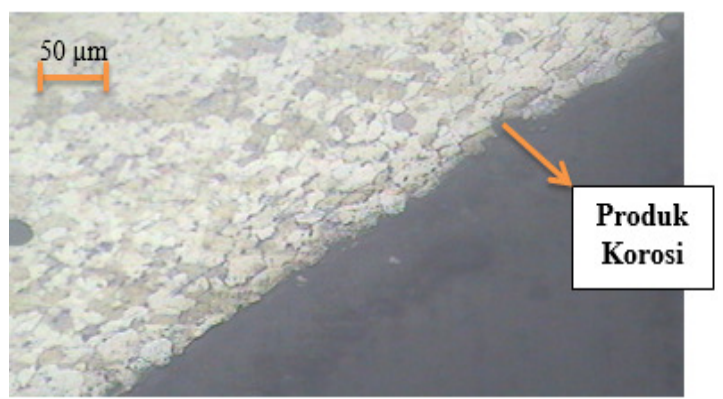

Gambar 18. Foto mikro baja SS400 dengan proteksi 4 buah aluminium ukuran $0,5 \times 4 \mathrm{~cm}$ setelah perendaman 28 hari 
Gambar diatas menunjukkan bahwa proteksi yang dihasilkan 4 buah aluminium ukuran 0,5 x $4 \mathrm{~cm}$ sangat efektif menurunkan serangan korosi pada baja SS400, pendistribusian anoda yang merata dapat meningkatkan luasan proteksi pada permukaan logam dikarenakan perpindahan elektron terjadi pada semua sisi katoda, dengan menyempitnya jarak antara ujung anoda dan katoda maka nilai hambatan material akan semakin kecil sehingga hambatan yang diterima anoda untuk mendistribusikan arusnya juga semakin kecil. Dibandingkan dengan ukuran variasi yang lain variasi ini memiliki kinerja yang paling baik. Hasil foto mikro diatas menunjukkan bahwa pola korosi yang terjadi adalah korosi sumuran, hal ini dibuktikan dengan ratanya ukuran rongga yang terjadi pada setiap sisi logam.

\section{KESIMPULAN}

Dari hasil penelitian yang dilakukan dapat diambil kesimpulan sebagai berikut:

1. Nilai laju korosi baja SS400 memiliki nilai yang berbeda pada setiap variasi pembagian jumlah anoda korban aluminium. Baja SS400 tanpa proteksi anoda korban memiliki ratarata nilai laju korosi sebesar 0,2223 $\mathrm{mm} /$ tahun, pada baja dengan 1 buah aluminium $2 \times 4 \mathrm{~cm}$ nilai rata-rata laju korosi berada pada angka 0,1677 mm/tahun. Baja SS400 dengan 2 buah aluminium dengan ukuran $1 \times 4 \mathrm{~cm}$ memiliki rata-rata laju korosi sebesar 0,1462 $\mathrm{mm} /$ tahun dan baja SS400 dengan 4 buah aluminium dengan ukuran 0,5 x $4 \mathrm{~cm}$ memiliki rata-rata laju korosi sebesar $0,1067 \mathrm{~mm} /$ tahun.

2. Laju korosi baja SS400 tanpa proteksi anoda korban memiliki nilai laju korosi paling besar, sedangkan nilai laju korosi terendah dihasilkan 4 buah aluminium dengan ukuran $0,5 \times 4 \mathrm{~cm}$. Semakin meratanya pendistribusian anoda korban maka jangkauan proteksi akan semakin luas sehingga anoda korban dapat bekerja bekerja dengan baik.

3. Hasil observasi mikro baja SS400 tanpa anoda korban menunjukkan banyaknya rongga yang muncul akibat serangan korosi, sedangkan pada baja SS400 yang diproteksi anoda korban jumlah rongga menurun drastis, dengan kinerja terbaik dihasilkan anoda korban 4 buah aluminium dengan ukuran 0,5 $x 4 \mathrm{~cm}$.

4. Jenis korosi yang terjadi pada spesimen uji setelah proses perendaman adalah korosi merata dengan ukuran dan kedalaman rongga relatif sama pada setiap sisinya.

\section{UCAPAN TERIMAKASIH}

Penulis pada kesempatan ini mengucakan terimakasih kepada semua pihak yang membantu baik berupa materi maupun pikiran sehingga penelitian dan paper ini dapat terselesaikan.Yang ke dua penulis mengapresiasi Jurusan Teknik Mesin atas fasilitas yang dipergunakan dalam penelitian ini.

\section{DAFTAR PUSTAKA}

Fontana, Mars G., 1986, Corrosion engineering, 3th Edition, Mc Graw Hill Co., New York.

Morgan J., H., 1987, Cathodic protection, National Association of Corrosion Engineers (NACE) 2nd Edition.

Muhsinin N.M., Kurniawan B.A., 2012, Pengaruh polutan terhadap karakteristik dan laju korosi pada baja AISI 1045 dan stainless steel 304 di lingkungan muara sungai, Jurnal Teknik Pomits, 1(1), 27-34.

Putra A., Rochani I., Ikhwani H., 2014, Analisa proteksi katodik dengan menggunakan anoda tumbal pada pipa gas bawah tanah pt, Pupuk Kalimantan Timur dari stasiun kompressor gas ke Kaltim-2, Jurnal Teknik Pomits, 2(1), 1-6.

Rey P.D., Prayitno D., 2015, Pengaruh aluminizing (al-cu) terhadap laju korosi sambungan las busur rendam tabung gas elpiji $3 \mathrm{~kg}$, Jurusan Teknik Mesin. Fakultas Teknologi Industri, Universitas Trisakti.

Sulistioso G.S., 2012, Analisis korosi dari SS 440C pada media air tawar dan air laut, Jurnal Teknik ITS, 1, G75-G77.

Widharto S., 1997, Karat dan pencegahannya, Pradiya Paramitha, Jakarta.

Wiludin A., Soepomo H., 2013, Analisa teknis dan ekonomis penggunaan ICCP (Impressed Current Cathodic Protection) dibandingkan dengan sacrificial anode dalam proses pencegahan korosi, Jurnal Teknik ITS, 2(1), 23-27. 